\title{
FIGO Staging System and Modified World Health Organization [WHO] Prognostic Scoring System for Gestational Trophoblastic Neoplasms
}

National Cancer Institute

\section{Source}

National Cancer Institute. FlGO Staging System and Modified World Health Organization

IWHOI Prognostic Scoring System for Gestational Trophoblastic Neoplasms. NCI

Thesaurus. Code C99408.

A system for defining prognosis for gestational trophoblastic neoplasia. In this system, the FIGO stage is represented by an Roman numeral, followed by the modified WHO score depicted as an Arabic numeral and separated by a colon (e.g., Stage II:4, Stage IV:9). Scores of 0-6 are considered low-risk and scores greater than 6 are considered high-risk. 